\title{
“Normalización” de la crisis y posición estratégica empresarial durante la expansión de la economía del salitre
}

\author{
Sergio González Miranda \\ Universidad Arturo Prat. Iquique, Chile. \\ Email:pampino50@gmail.com
}

\begin{abstract}
Resumen: Este trabajo aborda el período de mayor expansión de la economía del nitrato chileno, cuando estuvieron vigentes las combinaciones salitreras (1884-1911), entendidas como un cartel o trust empresarial, generando una posición estratégica de los empresarios, pero que influyeron hasta el final del ciclo del salitre (1920-1930). Se plantea la hipótesis que las medidas -privadas y públicas- tomadas frente a una recurrente percepción social de crisis que enfrentaba la industria del salitre, entre ellas la combinación salitrera, habrían controlado -normalizando- la economía, a tal punto que la percepción de crisis se habría internalizado entre los actores (empresarios salitreros y funcionarios públicos) como una parte integrante de su conducta cotidiana, afectando la capacidad prospectiva, por una parte, y de innovación, por otra.
\end{abstract}

Palabras clave: economía salitrera, combinación salitrera, normalización de la crisis, percepción de crisis.

\section{"Normalization" of the crisis and corporate strategic position during the expansion of nitrate economy}

\begin{abstract}
This work deals with the period of grater expansion of Chilean nitrate economy, when saltpeter compounds (Nitrate Combinations) were valid (1884-1911), understood as a cartel or business trust, generating a strategic position of the entrepreneurs, but that influenced until the end of the nitrate cycle (19201930). We state the hypothesis that the measures -private and public- taken in the face of a recurrent social perception of crisis confronting the nitrate industry, among them saltpeter compound, would have controlled -normalizing- economy, to the extent that the perception of crisis would have been internalized among actors (nitrate entrepreneurs and public servants) becoming part of their daily conduct, affecting their prospective capacity, on one hand, and innovation, on the other.

Keywords: nitrate economy, saltpeter compound, normalization of crisis, crisis perception.
\end{abstract}

\section{“Normalização” da crise e posição estratégica das empresas durante a expansão econômica do salitre}

Resumo: O presente artigo trata do período de maior expansão econômica do nitrato chileno, quando estiveram em vigor as combinações de nitrato (1884- 
1911), entendidas como um cartel ou trust empresarial, gerando uma posição estratégica dos empesarios, mas que influenciou até o fim do ciclo de nitrato (19201930). Sugere-se a hipótese que as medidas (privadas e públicas) tomadas contra a recorrente percepção social da crise que enfrentava a indústria de nitrato, entre elas a combinação de nitrato, teriam controlado -normalizando- a economia, na medida tal que a percepção de crise teria se internalizado entre os atores (empresários de nitrato e funcionários públicos), como parte integrante do seu comportamento cotidiano, afetando a capacidade de previsão, por um lado, e da inovação, por outro.

Palavras-chave: economia de nitrato, combinação salitrera, normalização da crise, percepção de crise.

$$
* * *
$$

\section{Introducción ${ }^{1}$}

Si la crisis es un acontecimiento o un evento, entonces se trata un fenómeno inesperado, al menos para la mayoría de los actores involucrados. Sin embargo, al estudiar el período de mayor expansión de la economía del nitrato (1884-1913), observamos que la crisis formó parte del discurso oficial y empresarial, justificando medidas asociadas a su (supuesta) existencia. Para la población regional, en la pampa y en la costa desde Pisagua hasta Taltal, la percepción de crisis formó parte de su vida cotidiana hasta la gran crisis de la década de 1930. También, como ha sido demostrado, esta percepción de crisis acompañó a los pampinos de los últimos campamentos salitreros, Pedro de Valdivia y María Elena (Rodríguez y Miranda 2010), en décadas muy posteriores al fin del ciclo de expansión.

Planteamos la hipótesis que los empresarios salitreros, una vez concluida la Guerra del Pacífico y conocida la política salitrera del estado chileno, tomaron medidas bajo el argumento de una recurrente amenaza de crisis, que les permitió no solo organizarse en un trust o sindicato, sino regular la economía salitrera, a través del control de la producción total de nitrato de soda y, de paso, lograr una "posición estratégica” frente al estadonación chileno y, parcialmente, frente a los agentes de la cadena del comercio mundial de fertilizantes. Dicho control de la producción de salitre, a través de la definición de cuotas por oficinas salitreras, no necesariamente pudo haber tenido éxito en evitar la caída en el precio internacional de este producto entre 1884 y 1910, sino que se empleó ese temor a la crisis para justificar la colusión empresarial, como una herramienta supuestamente eficaz para evitarla. Es decir, más que una medida estrictamente económica fue política.

¿Fue un temor fundado la crisis salitrera en ese período? Alejandro Bertrand, escribiendo en 1910, señalaba que "la industria salitrera, en sus condiciones naturales de producción, no ha tenido ni está próxima a sufrir crisis alguna, pues las mayores bajas de precio del salitre siempre han dejado, sobre su costo de producción y la remuneración de los capitales invertidos, un margen ampliamente suficiente para una buena utilidad industrial" (1910:27). Empero, la percepción de crisis efectivamente fue una realidad. 
Cabe hacer la distinción entre crisis y percepción de crisis, donde la primera se sustenta en indicadores económicos bien determinados, generalmente asociados a "descensos de cualquier curva cíclica a cualquier escala" (Wallerstein 2007:146)², y la segunda apela a representaciones sociales (Araya 2012) ${ }^{3}$.

En rigor, en el de 1884-1911 el mercado internacional del nitrato chileno sufrió muchas fluctuaciones, por diversos motivos, desde problemas climáticos a políticos, pero ninguna que se aproximó a una verdadera crisis económica como la se enfrentaría en 1914 y en 1919 (Gráfico N¹) y con mayor razón a lo vivido en la década de 1930.

\section{Gráfico $N^{\circ} 1$ \\ Salitre exportado en quintales por las regiones salitreras de Tarapacá y Antofagasta entre 1883 y 1919.}

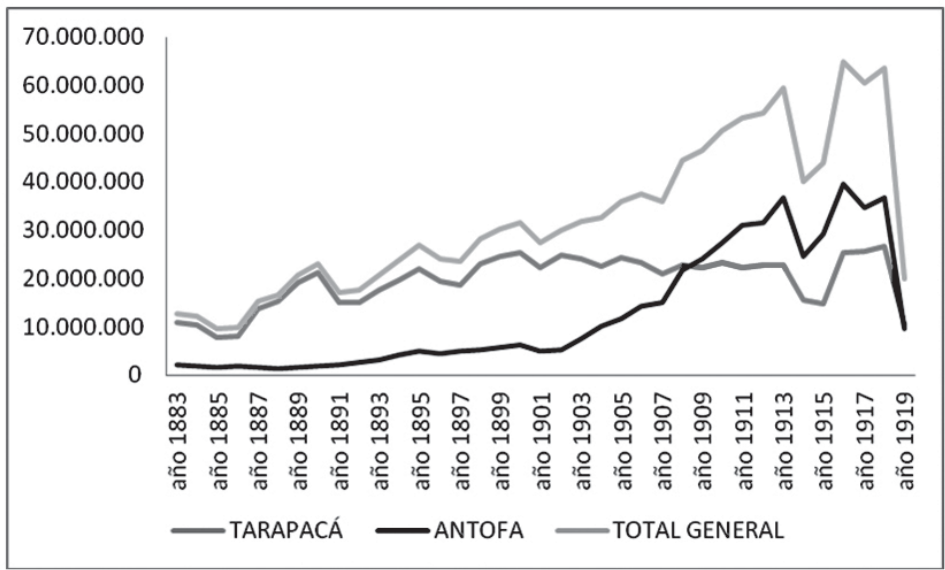

Fuente: Archivo Histórico Nacional. Santiago. Fondo del Salitre. Asociación de Productores de Salitre de Chile. Valparaíso 22 de noviembre de 1921.

La posición estratégica ${ }^{4}$ de los empresarios salitreros fue alcanzada cuando -en 1884- lograron por vez primera organizarse en un Comité Salitrero, que reunió a todos los productores, quienes se comprometieron ante un notario aceptar las cuotas asignadas, consiguiendo el ansiado monopolio de la producción del nitrato chileno ${ }^{5}$, el instrumento utilizado fue denominado “combinación salitrera”. Lo anterior les permitiría tener una capacidad de negociación privilegiada con estado-nación chileno y, supuestamente, evitar las fluctuaciones del precio internacional del salitre.

La primera combinación fue organizada en 1884 supuestamente para controlar una producción de nitrato de soda desregulada, como resultado 
de una competencia salvaje entre los propios salitreros ante la incertidumbre por el cambio de soberanía en Tarapacá, y frente a una coyuntura de crisis internacional del azúcar. Sin embargo, esta medida de corto plazo habría de transformarse en una política salitrera no estatal que duraría hasta la Primera Guerra Mundial. Entre 1884, el primer año de combinación, y hasta 1910, el último año de colusión, hubo 9 años de libertad en la producción salitrera y 18 años combinados (Cuadro $N^{\circ} 1$ ).

A partir de 1919 se iniciaría una etapa de crisis efectivas, producto del término del mercado de salitre refinado para objetivos bélicos, lo que obligaría a los empresarios a cambiar la organización que diseñaron en $1884^{6}$. Esta crisis post-bélica, escala gubernamental, obligaría en la década de 1920 a una discusión sobre una nueva política tributaria ${ }^{7}$, sin embargo, la intervención estatal se podrá observar recién en la década siguiente, llegando a su máxima expresión con la organización de un estanco salitrero a través de la Ley 3.350 que creó la Corporación de Ventas de Salitre y Yodo de Chile (COVENSA) en 1934.

El cuadro $N^{\circ} 1$ nos muestra los períodos de combinación salitrera y de libertad productiva.

\section{Cuadro $N^{\circ} 1$}

\begin{tabular}{|c|c|c|}
\hline Año & $\begin{array}{l}\text { Toneladas Métricas } \\
\text { de salitre }\end{array}$ & Tipo de organización de la producción \\
\hline 1880 & 223.974 & Libre \\
\hline 1884 & 558.720 & $1^{\circ}$ Combinación \\
\hline 1887 & 704.244 & Libre \\
\hline 1891 & 789.312 & $2^{\circ}$ Combinación \\
\hline 1894 & 1.098 .454 & Libre \\
\hline 1896 & 1.107 .045 & $3^{\circ}$ Combinación \\
\hline 1898 & 1.293 .947 & Libre \\
\hline 1901 & 1.259 .720 & $4^{\circ}$ Combinación \\
\hline 1906 & 1.656 .088 & $5^{\circ}$ Combinación \\
\hline 1911 & 2.449 .239 & Libre \\
\hline 1919 & 2.377 .831 & Asociación de Productores \\
\hline 1927 & 2.377 .831 & Libre \\
\hline 1929 & 2.898 .141 & Nueva Asociación \\
\hline 1931 & 1.425 .996 & COSACH \\
\hline 1933 & 705.958 & COVENSA \\
\hline
\end{tabular}

Fuente: Ministerio de Hacienda. La Industria del Salitre de Chile. Tomo I, Santiago, 1935, p.7. 
El Comité Salitrero fue creado en Iquique el 10 de junio de 1884. En su declaración de principios señala que "todas las personas que concurran á este convenio son aptas para ser miembros del Comité, sea que residan en Tarapacá, Tocopilla, Antofagasta, Aguas Blancas, Taltal o Valparaíso" (Schmidt 1884:12). Es decir, a pesar de las distancias físicas, de las diversas escalas tecnológicas ${ }^{8}$ y de las diferencias en los costos de producción, lograron la participación y la cooperación de todos los productores de nitrato de soda en Chile?

El primer presidente de la Junta Directiva de este Comité fue H.D. Schmidt, un alto ejecutivo de la Compañía alemana Gildemeister, pero era sabido que estaba detrás de esta iniciativa J.T. North, quien operaría desde Londres, ciudad donde se crearía el Nitrate Permanent Committee en 1886 que, junto a la Asociación Salitrera de Propaganda, organizada en Iquique en 1894, decidirían los destinos de la industria salitrera chilena, al menos hasta 1910.

Como podemos observar en el Cuadro $\mathrm{N}^{\circ} 1$, el control de las cuotas de producción no fue determinante para afirmar que sin combinaciones se estaría bajo una supuesta competencia salvaje donde terminarían dominando el mercado un pequeño grupo de empresas. Cabe reconocer que el capital chileno no quiso participar en este período post-bélico, posiblemente temiendo esa competencia salvaje, como lo señalara Carlos Aldunate Solar en el Consejo Salitrero de 1912:

(...) después vino una contracción que puso en aprietos a la industria, y a la cual aportaron algunos pocos; los industriales chilenos, demasiado nerviosos y quizás menos preparados que los extranjeros, se descorazonaron a las primeras dificultades, y creyeron su salvación al traspasar a los extranjeros sus maquinarias, etc., que hoy, con los altos precios, representan un gran negocio (Larraín 1912: XXII).

Posiblemente, esa fue la razón por la cual estas organizaciones quedarían en manos extranjeras, especialmente inglesas, las que no solo enfrentarían la percepción de crisis sino la transformarían en una herramienta política para consolidar su control de esta economía, por medio de un concepto que podríamos denominar "normalización de la crisis"10.

Cadahia y Velasco entienden por "normalización” de la crisis a "la capacidad para hacer de los sujetos que padecen la crisis el medio de su constante consolidación. Además de servir como marco explicativo...” (2012:8). En este caso se trata de la creación de las “combinaciones salitreras”, que fueron aceptadas como prevención a la crisis por todas las compañías salitreras que operaban en Chile, desde los cantones de Tarapacá por el norte hasta el cantón de Taltal, por el sur. Adicionalmente, fueron aceptadas por los gobiernos nacionales y sus agencias y agentes que operaban en el mercado internacional de los fertilizantes. 


\section{La percepción de crisis}

David Sánchez, siguiendo a Koselleck, nos recuerda que "el término Krísis es de origen médico. En un contexto hipocrático, Krisis es un cambio repentino en el curso o manifestación de una patología, pero sin que dicha variación posea un valor determinado” (2012:51), es por ello, que el historiador alemán Koselleck denominó de "patogénesis" a la condición de la sociedad contemporánea. Siguiendo esa misma metáfora médica, las medidas que empresarios y funcionarios tomaron para "evitar" la crisis de la economía salitrera, podrían asemejarse a la administración de una vacuna, para generar una respuesta inmunológica, sin arriesgar el negocio salitrero privado, por un lado, y la renta pública, por otro. En otras palabras, se provocaron intencionalmente "pequeñas crisis" dentro del marco de la economía del nitrato chileno, como el cierre temporal de algunas fábricas u oficinas salitreras, generando una menor producción y, por lo mismo, también una menor exportación, disminución del stock y una cesantía a baja escala, etc. Consiguiendo supuestamente como beneficio un incremento del precio internacional de los fertilizantes al disminuir la oferta de nitrato de soda, asegurando por esa vía la misma ganancia para los empresarios y la misma renta para el fisco respecto de un escenario sin combinación salitrera.

Gonzalo Velasco, siguiendo a Canguilhem, señala que "la crisis del organismo es una ocasión para demostrar la creatividad inmanente a la vida. Lo patológico no es así el elemento exógeno que es preciso mantener en el exterior mediante la prevención; antes bien, el organismo sano incorpora lo patológico, lo asume en su propia normatividad” (2012:204). Mutatis mutandis, podríamos decir que, para el caso de la economía del nitrato hacia 1884, el elemento patológico externo pudo haber sido la crisis del azúcar ${ }^{11}$. Entonces, la creación del Comité Salitrero -la organización de los empresarios- y la combinación salitrera fueron el actor y su herramienta para superar una crisis coyuntural.

Sin embargo, como veremos más adelante, lo que realmente alarmó a salitreros y funcionarios públicos fue un factor endógeno: el rápido aumento de salitre entre 1882 y 1884, lo que Wallerstein denomina "la competencia salvaje” (2007:152). En palabras del entonces Jefe Político de Tarapacá, Francisco Valdés Vergara:

La producción excesiva de los últimos años ha destruido por completo la base comercial de dicha industria i los salitreros se hallan condenados, desde hace algún tiempo, a sostener entre si una competencia que a todos les lleva a fatal ruina i que perturbará también la condición económica de la República si no se llega pronto a una solución que restablezca aquella base i que permita a los productores adoptar como regla para el desarrollo de sus trabajos, no el trabajo de sus vecinos, sino el precio del artículo en los mercados de consumo (1884:5).

De esa forma se abría la puerta a la colusión empresarial como la 
herramienta necesaria para evitar la competencia salvaje y la con ella la crisis total que arrastraría al propio estado nacional ${ }^{12}$.

En cierta forma, "las combinaciones” fueron una medida patológica, en el sentido que fue una colusión contraria a la ética capitalista liberal, pero que terminó por ser asumida en su propia normatividad por el organismo, en este caso por el estado-nación chileno. Miller y Greenhill, analizando la cadena internacional de comercialización del salitre, señalan:

“el problema principal que afectó a la cadena en este (bajo la administración chilena) se derivó en el desequilibrio potencial -en el corto plazo- entre la oferta chilena del salitre y la demanda extranjera, que era inelástica con respecto del precio. Esto produjo una serie de acuerdos colusorios entre los productores, las combinaciones de salitre, a las cuales el Estado inicialmente se opuso pero luego fomentó” (2011a:126).

Efectivamente, por principios, un estado-nación que había optado en 1881 por una política salitrera de plena libertad económica, no podía ver con simpatía una colusión empresarial, aunque se tratase de una medida coyuntural, por ello, se levantaron voces críticas:

Bajo ese régimen se han formado, á la vista y paciencia del Gobierno de Chile, sindicatos ó combinaciones de salitreros que, con el fin aparente de regular la producción y de fomentar el consumo del salitre en los países de Europa, han practicado en realidad un monopolio odioso, destinado á limitar la producción y la exportación del salitre y á subir artificialmente su precio de venta en las plazas extranjeras. (Editorial de La Libertad Electoral del 31 de julio de 1893).

El control de la producción de salitre a través de cuotas por oficinas, determinadas por las combinaciones, sacaba temporalmente a algunas salitreras de las estadísticas de la Asociación Salitrera de Propaganda, el gremio empresarial del período, generando crisis a baja escala -por cantón salitrero- pero que, supuestamente, evitaba una crisis más profunda.

Si bien hubo resistencia, como hemos visto, esta medida terminó por ser acepta -e incluso promovida- por el estado-nación chileno a través de sus funcionarios públicos. De tal modo, la "normalización” de la crisis por parte de los empresarios salitreros, terminaría siendo la principal herramienta de la "constante consolidación" de su "posición estratégica" frente al estado-nacional.

Algunos de los rasgos de la concentración industrial y comercial y, específicamente, de un trust o sindicato empresarial, como el salitrero, siguiendo a Alejandro Bertrand, serían: elevarse al rango de potencia financiera, la sobre capitalización (stock watering), el alza artificial de los precios, la ruina del competidor individual, y la influencia corruptora (1910:70). Estos rasgos serían la base de la posición (política) estratégica de este 
grupo empresarial en la sociedad chilena.

Lo anterior explicaría, por ejemplo, el papel del gobierno chileno y sus funcionarios públicos en un suceso tan grave como la masacre obrera de diciembre de 1907 (Devés 1988), en plena quinta combinación (ver Cuadro $\mathrm{N}^{\circ} 1$ ). A pesar de la magnitud de este movimiento y el trágico desenlace del mismo, las cifras de producción y exportación de 1907 y 1908 casi no sufrieron variaciones, debido al control empresarial; tampoco se vieron afectadas las entradas fiscales en esos años. ${ }^{13}$ Cabe señalar otro momento similar: la segunda combinación se acordó el primero de enero de 1891, es decir, en plena Guerra Civil. El diario La Patria del martes 24 de marzo de ese año, reproducía una información proveniente del South American Journal, donde se señalaba que:

La situación de la industria salitrera, se ha complicado sobremanera, con la insurrección chilena; para coronarlo todo, se asegura que el Gobierno ha prohibido la exportación del nitrato de soda. Curioso estado de cosas es éste, si se considera que la principal entrada del Fisco chileno proviene del derecho de exportación que paga el salitre.

En realidad la segunda combinación salitrera establecía, en el primer punto de su acuerdo, que: "Cada uno de los firmantes de este convenio, en el carácter en que comparece o por la sociedad que representa, conviene que los demás otorgantes en no trabajar en sus respectivas oficinas salitreras, sino siete meses en el año 1891" (La Patria, martes 7 de abril de 1891). No era el Gobierno de Balmaceda el que controlaba esta industria cuando se produjo la Guerra Civil. Esta combinación se prolongó hasta 1893, sin mayores novedades.

\section{La política salitrera de los industriales y la posición estratégica}

La estrategia empresarial de 1884 fue, en definitiva, la política salitrera (chilena) predominante sobre los vastos territorios del desierto de Atacama que contenían mantos de caliche. A diferencia del período peruano, donde fue el estado-nación el que intentó implementar una política salitrera, especialmente bajo el Gobierno de Manuel Pardo (1872-1875), aquí quedó en manos de los empresarios la iniciativa de definir un proyecto político sobre esta industria. La distancia de las regiones salitreras del centro político nacional, no impidió que algunos círculos de opinión pública observaran con desconfianza lo que acontecía en el desierto de Atacama. El diario "La Libertad Electoral” del 13 de abril de 1887, en su crónica titulada “cuestiones salitreras”, en una de sus partes señalaba:

La Combinación salitrera era una poderosa asociación que tenía por objeto limitar la producción del salitre a la cantidad que los productores interesados estimaban suficiente al consumo europeo con el 
fin de mantener el precio del artículo.

De esta manera se llegó a constituir un verdadero monopolio de los productores asociados, con grandes ventajas para la jeneralidad de ellos, con no pocos inconvenientes para el progreso de la industria, i con manifiesto detrimento de las rentas fiscales. Por este camino se limitó la esportación del salitre a 4.296,625 quintales métricos en 1885, i a 4.527,882 respectivamente en 1886. Estas esportaciones tuvieron un valor de $20.654,122$ pesos de 38 peniques en 1885 , i 10.429,096 pesos en 1886 .

Como se vé, estas son las gruesas cifras de nuestras esportaciones, que solo alcanzaron a 51.239,149 pesos en 1886, i de las rentas nacionales ordinarias que se calcularon en \$36.000,000 en el mismo año. No se necesita hacer desfilar más números ni entrar en otras comparaciones para manifestar que la Combinación salitrera ha tenido entre sus manos la llave de la producción nacional i de las entradas del fisco.

En estos párrafos los editorialistas de La Libertad Electoral han logrado descifrar que las combinaciones no eran (solamente) una herramienta de emergencia para enfrentar una crisis, sino (también) una colusión empresarial para lograr el monopolio de este producto. La frase que señala "la Combinación salitrera ha tenido entre sus manos la llave de la producción nacional i de las entradas del fisco", expresa la "posición estratégica" que este grupo empresarial alcanzó en ese período en Chile.

La palabra crisis rondó siempre por las cabezas de toda la sociedad regional y nacional, a tal punto que la misma Editorial ya citada del periódico La Libertad Electoral, dice en otra de sus partes:

En esta orijinalísima industria salitrera la facilidad de la producción trae por consecuencia precisa frecuentes desequilibrios entre el consumo i la producción. De aquí las crisis periódicas a que parece condenada no obstante ser tan poderosa i tan llena de vitalidad.

Incluso un reconocido personaje balmacedista, como Manuel Salinas ${ }^{14}$, delegado fiscal de salitreras en 1889, tuvo esa misma percepción y aceptó la idea de las crisis periódicas, a saber:

Las crisis a que periódicamente está sometida la industria salitrera a causa de su mismo desarrollo manifiestan la necesidad de que arbitren los recursos convenientes para abrir nuevos mercados al consumo, a fin que se pueda encontrar fácil expendio a la producción de las oficinas hoy establecidas o que se establezcan en lo sucesivo a medida que sean entregados a la explotación las oficinas y terrenos salitrales de propiedad fiscal (1890:28).

La diferencia en la percepción de crisis de Salinas respecto de la 
difundida por los empresarios salitreros está en la solución al problema, éste plantea que deben abrirse nuevos mercados y aumentar en número de oficinas en funcionamiento. En cambio los salitreros recurrieron a la colusión y se opusieron a los remates de terrenos (estacas salitreras) fiscales que, al fin y al cabo, era entonces la única herramienta que poseía el estado chileno para desbaratar la colusión salitrera.

Como hemos señalado, el supuesto beneficio de las combinaciones industriales era la estabilidad del precio en el mercado internacional, pero las fluctuaciones que sufría el precio del nitrato chileno, generado por dealers que especulaban con el precio, fue un dolor de cabeza de las autoridades chilenas de la época. Como bien lo señalaba el cónsul de Chile en Le Havre, relatando el expendio de nitrato en Francia hacia 1895, "cuando el Nitrato pasa de 20 frs. es demasiado caro y su consumo disminuye" (Campaña 1897:32), básicamente porque había disponible en Europa una variedad de otros tipos de fertilizantes, divididos en abonos fosfatados, potásicos y azoados que ofrecían -más que mejores precios o mayor calidad- una estabilidad en los precios que le permitía a los consumidores (agricultores) programarse según sus necesidades.

Algunos analistas de la época se enfocaron en la incertidumbre que la especulación generaba en los mercados, sugiriendo una nueva política salitrera de centralización de las ventas. Uno de ellos, que oculta su nombre detrás del seudónimo "salitrero", considera que con la centralización:

Se economizan los tres millones de libras esterlinas que hoy se guardan los intermediarios; con ella fijaremos el precio del salitre, sino para siempre, al menos por períodos largos, evitando así a los comerciantes al detalle las incertidumbres y pérdidas que ahora sufren con las continuas mutaciones de ese precio, con ella, y solo con ella, será posible la propaganda comercial, ya que ésta exige stock y el stock exige centralización (1916:5).

Esta percepción de incertidumbre estaba en la cadena de comercialización de la mercancía y no en la producción de la misma. El escaso apoyo que entregaba el Estado-nación chileno a la propaganda salitrera, por un lado, y el creciente protagonismo de los especuladores "como fijadores del precio del salitre", por otro, se transformó en un nudo gordiano. Esto fue denunciado años antes por Alejandro Bertrand, donde responsabiliza también a las combinaciones: "las combinaciones salitreras no han tenido, como podían tenerla, ninguna acción en la estabilización de los precios, pues no han sido, sino combinaciones incompletas que han aprovechado únicamente los especuladores” (1910:21). Si las combinaciones no estabilizaron los precios del salitre en el mercado internacional, entonces ¿ंcuál fue su propósito?, más que económico fue político: alcanzar una posición estratégica dentro de la estructura del poder en Chile ${ }^{15}$.

Una mirada retrospectiva no puede sino encontrar contradicciones en esta percepción de crisis y la conducta de los actores de la época. Hablar 
de crisis periódicas durante el ciclo de expansión del nitrato, cuya extensión temporal podría estar abarcando entre treinta o cincuenta años, según los autores que revisemos, es una contradicción, porque "en su origen crisis estaba referida a un período de tiempo finito, a una situación transitoria y resolutiva, algo que en su deriva contemporánea ha terminado por diluirse..." (Sánchez 2012:54). A fortiori, el concepto de expansión expresa una idea contraria a la de crisis, pues hace referencia a un momento de auge, al mejor período de un ciclo más amplio, en otras palabras, hablar de crisis durante la “expansión del nitrato” sería, en cierta forma, un oxímoron. Sin embargo, la crisis fue parte fundamental no solo del discurso empresarial sino de su exitosa estrategia económica de corto y mediano plazo, pero desastrosa a largo plazo.

El éxito de esta estrategia incluso tuvo un impacto favorable en el salario de los trabajadores por un breve período, como lo demuestra Mario Matus:

En consecuencia, lo que permitió que el jornal salitrero real se elevara entre 1899 y 1905 fue una feliz coincidencia entre un entorno externo favorable - que posibilitó un desempeño positivo de la actividad salitrera, que puede seguirse en el crecimiento del $N^{\circ}$ de oficinas y trabajadores y que redundó en un crecimiento del jornal nominal- y la ausencia de un entorno inflacionario.

Sin embargo, fue un auge (Matus le denomina “fulgor”) a corto plazo, pues como lo señala este mismo autor:

A renglón seguido es posible identificar una larga fase descendente, que se inició con una brusca caída desde un jornal de \$ 12,7 en 1905 a \$ 6,4 en 1909, y que luego continuó con un descenso menos abrupto -de \$ 7,1 a \$ 4,3- entre 1911 y 1919. Al final de esta fase el jornal salitrero enfrentó lo más parecido a una muerte, cuando su valor real se redujo a un tercio de lo que había sido en 1905. (2013:521)

Wallerstein afirma que, en el contexto del beneficio de corto o mediano plazo, la conducta cooperativa de los empresarios les puede llevar a acceder "esporádicamente a realizar cierta redistribución del superávit entre los estratos obreros para recrear y expandir la demanda efectiva, y permitir así que la expansión se renueve” (2007:153). Lo anterior podría explicar el alza de los salarios entre 1899 y 1905, pero sabemos que ya en 1907 de la pérdida de valor del peso respecto de la libra esterlina; precisamente la principal demanda de la huelga de diciembre de 1907 fue el pago de los jornales a razón de un cambio fijo de 18 peniques.

La brevedad del período de auge es también una contradicción que explica la emergencia de los movimientos sociales motivados por pliegos de peticiones acordes a la industria en que participaban, pues al igual que los patrones (empresarios salitreros) también actuaron gremialmente. Curiosamente, la principal organización obrera que surge en pleno auge salitrero se 
denominó “Gran Combinación Mancomunal Obrera”, liderada por el obrero portuario Abdón Díaz, y fue la plataforma para la redacción de los Memoriales Obreros de 1904 (Reyes 1973), que fueron entregados al Presidente Germán Riesco.

\section{Desde la competencia salvaje a corto plazo, el cooperativismo empresarial de mediano plazo, hasta la crisis definitiva a largo plazo}

Veíamos con Mario Matus que los salarios tuvieron una mejora significativa en un corto plazo, en el momento de mayor auge de esta economía (1899-1905), para después iniciar un descenso definitivo entre 1911 y 1919. Lo anterior fue solo un reflejo de lo acontecido en esta industria bajo la estrategia salitrera del cooperativismo, donde los empresarios actuaron como un sindicato.

Wallerstein afirma que "a corto plazo, el acumulador de capital es salvaje. A mediano plazo es cooperativo. Y a largo plazo el sistema queda socavado” (2007:152). Este autor, nos dice que “a fin de resolver las contradicciones económicas a corto plazo, los acumuladores del capital, tienden a desplazarse conjuntamente -actuando como un gremio- hacia una conducta “cooperativa” del medio plazo” (2007:153), lo que podríamos interpretar para el caso salitrero, que el temor a crisis y a la competencia entre ellos, les llevó hacia una conducta gremial (el Comité Salitrero de 1884) de tipo cooperativo, expresado en las combinaciones salitreras que, efectivamente, tuvieron una duración de mediano plazo (1884-1910). Para expresarlo en las propias palabras de quienes idearon el Trust salitrero:

"Mientras la producción del salitre (bajo la libre competencia establecida por el Gobierno de Chile) seguía una marcha tan extraordinaria los mercados de consumo solo exijian una parte de esa producción, haciendo decaer progresivamente el precio del artículo hasta llegar á un término que imponía una pérdida efectiva á los productores y que les anunciaba una inmediata y desastrosa liquidación...” (Schmidt 1884:4)

Esta fue, siguiendo a Wallerstein, la etapa salvaje de la competencia. Continúa el presidente del directorio del Comité Salitrero:

Fueron estas condiciones las que estimularon el buen juicio de los salitreros para acercarse y combinarse. La tarea que se nos ofrecía no podía ser más fácil. El salitre es una sustancia de consumo necesario, limitado y conocido. El único país que lo produce es Chile, y nosotros los poseedores de la materia prima y sus elaboradores. Hacernos una mutua competencia, produciendo sin limitación, era causar nuestra ruina con provecho exclusivo de los consumidores de mercados extranjeros” (Schmidt 1884:4). 
A partir de allí se inicia la etapa cooperativa de los salitreros, conscientes que estaban frente a una gran oportunidad para sus intereses de corto y mediano plazo. La prospectiva de los salitreros combinados fue la siguiente:

El resultado práctico que buscábamos con la limitación de la producción no se dejó esperar, puesto que en Junio mismo subió considerablemente el precio del salitre. No hay razón alguna para que se produzca una baja, desde que el salitre no tiene competidor entre sus materias similares, dentro de ciertos precios (Schmidt 1884:5).

Con esta visión del comercio de los fertilizantes, el futuro de la industria salitrera, parafraseando a Wallerstein, quedó socavado. El nitrato de soda tuvo siempre variados competidores como el sulfato de amoniaco, el nitrato de cal, el ácido nítrico, la cianamida de cal, el nitrato de potasa, etc., lo que fue descuidado por salitreros y los gobiernos chilenos. El gráfico $\mathrm{N}^{\circ}$ 2, nos muestra como a partir de 1894, comenzó a decaer porcentualmente la participación del salitre en el mercado internacional de los fertilizantes.

\section{Gráfico $N^{\circ} 2$}

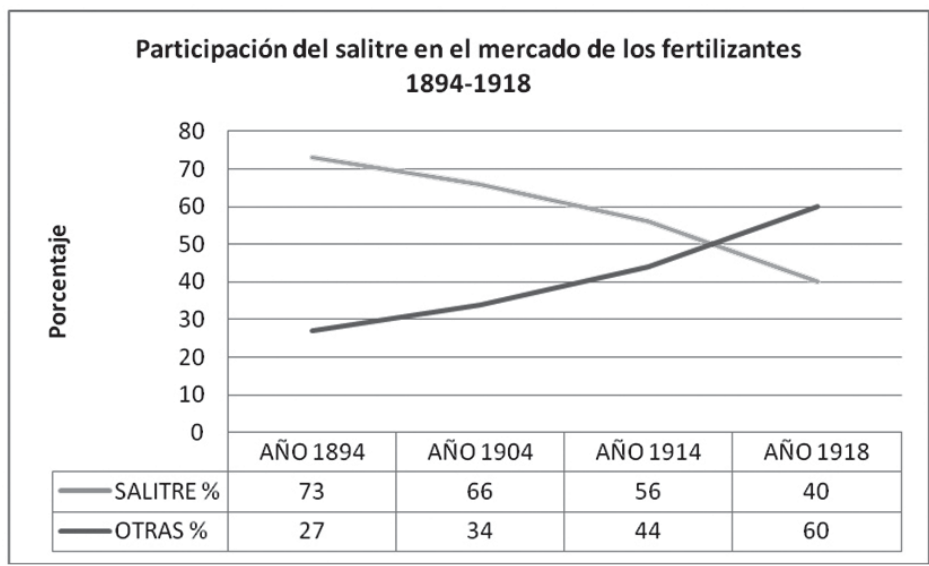

Fuente: Bertrand 1918:9

Según Bertrand, “la disminución de los porcentajes correspondientes al salitre, ya manifiesta de 1894 a 1913, demuestra que este fenómeno no es en su origen una consecuencia de la guerra” (1918:9). Entonces ¿cuáles serían las causas que sugiere el más versado de los especialistas en el mercado internacional de los fertilizantes?

El constante aumento del costo de producción, debido ante todo a la 
disminución media de la materia prima explotada; en segundo término al hecho que la tecnología salitrera no ha progresado a la par con la de las industrias competidoras, y en tercero, a la falta de organización del comercio salitrero, y a las consiguientes perturbaciones debidas a la especulación (Bertrand 1918:9).

La razón de esta imprevisión se debe a un problema propio de esta estrategia empresarial, como nos orienta el análisis de Wallerstein sobre las crisis capitalistas, a saber: "el buen funcionamiento del sistema depende de ciertas garantías político-culturales que aseguren la operatividad del citado comportamiento competitivo que empuja al empresariado individual hacia la creación de mayor demanda efectiva y hacia la cooperación con empresarios competitivos a fin de reducir los trastornos de la actividad económica” (2007:152). Lo anterior expresa lo que aconteció con la economía salitrera a partir de 1884: los empresarios se organizaron cooperativamente para garantizar una mayor demanda, por un lado, y disminuir los riesgos de una competencia feroz entre ellos. Esta medida para enfrentar una coyuntura, fue transformándose en una estrategia de mediano plazo, cuyas consecuencias fue pagada a largo plazo por toda la sociedad nacional, especialmente por la sociedad pampina, que enfrentó el drama de la cesantía y el desarraigo.

El argumento del fantasma de la crisis fue pieza fundamental la normalización de esta economía durante el período de mayor auge (1884-1911). Se "normalizó" la economía salitrera a tal punto que la percepción crisis se internalizó entre todos los actores (empresarios salitreros y funcionarios públicos $)^{16}$ como una parte integrante de su conducta cotidiana, afectando la capacidad prospectiva, por una parte, y de innovación, por otra. A pesar de la evidencia de pérdida de competitividad del nitrato chileno (Gráfico $\mathrm{N}^{\circ}$ 2), tanto la innovación tecnológica como la propaganda salitrera nunca fueron valoradas de acuerdo a los requerimientos de dicha competencia. En 1926, el ingeniero Carlos Hurtado anotaba al visitar las salitreras que: "se puede constatar varios progresos y una gran actividad investigadora de parte de muchas oficinas, que para un observador del sur acostumbrado siempre a oír que la industria salitrera usa una técnica muy rudimentaria se le presentan del todo nuevo” (1926:175). Para entonces, se había iniciado una carrera tecnológica contra el tiempo, solo el método Guggenheim tendría cierto éxito. Demasiado tarde: el salitre sintético -de tecnología alemana- había ganado esa carrera iniciada antes de la Primera Guerra Mundial, conflicto bélico que le ofreció un paréntesis de bienestar a la industria del nitrato chileno hasta 1918, pero que al concluir desnudó todas las deficiencias gerenciales y tecnológicas de la industria del nitrato chileno..

Las combinaciones habían sido un paraguas de confianza entre los salitreros, evitando la competencia y asegurando una tasa de ganancia, lo que desincentivó la innovación tecnológica y la administración pública, llegándose al absurdo que el sistema Shanks de lixiviación de nitrato de soda, introducido en el período peruano entre 1876 y 1878, fue el que predominó hasta 1920 con escasas modificaciones. El estado-nación de Chile, por 
su parte, se aseguró un tributo salitrero relativamente alto para sus gastos sin promover la ciencia y la tecnología. La mentada universidad del salitre jamás fue creada. Belisario Díaz Ossa, señalaba con molestia en 1926, cuando expone en la "semana del salitre" sobre la creación en 1918 del Instituto Científico e Industrial del salitre, que "la nota discordante, en este concierto de cooperación y trabajo, la han dado el Gobierno y los Ministros de Hacienda, pues a pesar de haber prometido ayudar al Instituto con una modesta subvención hasta hoy no han contribuido con la más mínima suma, esto es lo que se llama proteger la Industria Salitrera” (1926:173).

Alejandro Bertrand, siguiendo al profesor francés Chastin, quien estudió la relación entre los trust y las combinaciones industriales, concluye que "a la larga, los consorcios no tienen efecto permanente en el alza de los precios, sino más bien un efecto regulador durante su vigencia, impidiendo las oscilaciones violentas de éstos” (1910:63). Lo anterior fue cierto para la industria del salitre respecto del efecto permanente en los precios, pero no con relación a las oscilaciones de éstos. El precio internacional del nitrato chileno se caracterizó más bien por su inestabilidad producto de la especulación de los dealers, lo que facilitó la entrada de productos competidores. Un caso poco estudiado fue la especulación de empresas navieras que compraban el producto al costado del barco y, aprovechando la demora del viaje, lo vendían dependiendo de esas fluctuaciones. La estabilidad que generaron las combinaciones salitreras se logró en otro plano, al interior de la sociedad y economía salitreras, a través del convencimiento de haber alcanzado una “normalización” de la crisis, pero sin que la percepción sobre ella desapareciera totalmente. Lo anterior puede explicar las conductas de los obreros del salitre y de las autoridades nacionales, al negarse a aceptar que se estaba a partir de 1919 en una fase de declinación definitiva de esta industria, los primeros con su insistencia en regresar a las oficinas ante cualquier llamado de enganche y, los segundos, al no implementar políticas públicas que estimularan la competitividad del nitrato chileno, recién en 1926 se realizará la Semana del Salitre que reuniría a las principales autoridades del país para estudiar el problema salitrero. ¿Por qué ante la evidencia internacional de la crisis salitrera hubo resistencia al cambio? La respuesta puede ser porque las crisis habían pasado a formar parte de la cotidianidad, se habían internalizado en la sociedad nacional como un fenómeno "normalizado".

\section{Las contradicciones de la estrategia}

Como hemos señalado, después de 1884, con la creación de la primera combinación salitrera, vino el período “cooperativo”, donde los empresarios organizan un sindicato o cartel, a través de organizaciones como el Comité Salitrero, primero, y el Nitrate Permanent Comittee y la Asociación Salitrera de Propaganda, después. Como muy bien lo menciona Wallerstein "a fin de resolver las contradicciones económicas a corto plazo, los acumuladores de capital, tienden a desplazarse conjuntamente -actuando como un gremio- hacia su conducta cooperativa de mediano plazo” (2007:153). 
Las contradicciones a corto y mediano plazo, que los salitreros debieron enfrentar, fueron de dos tipos:

1. Hubo una contradicción que se produjo al interior de los propios salitreros que compartieron la primera combinación. A partir de la segunda combinación, algunos salitreros de nacionalidad chilena observaron un control de la combinación por parte del capital inglés, expresado en el Permanent Nitrate Comittee, que respondía a sus intereses, en contra supuestamente los del estado-nación chileno.

La crítica más notoria y directa la realizó Francisco Oliván, quien participó activamente la primera combinación salitrera, pero que se opuso terminantemente a la segunda y tercera combinaciones, escribiendo un libro (que compila artículos periodísticos de su autoría) titulado: "La combinación salitrera y sus hechuras, sus graves perjuicios y su remedio”, editado en Valparaíso por la imprenta Universo el año 1893. También a través periódicos hubo una corriente de opinión opositora a la colusión salitrera, como La Libertad Electoral, El Heraldo, El Mercurio, La Patria y El Ferrocarril. ${ }^{17}$ La crítica estuvo centrada en una defensa de los intereses nacionales. Si bien nunca decayó del todo esta perspectiva crítica, especialmente dentro del partido Liberal Democrático o Balmacedista, comenzó a mermar con la llegada del nuevo siglo, especialmente porque desde el estado-nacional se apoyó a las combinaciones.

2. El otro frente de contradicción que enfrentaron los salitreros provino desde el Gobierno chileno y sus funcionarios públicos, a través de una medida que, sostenemos, fue la causa del término de las combinaciones: la venta de nuevos terrenos salitrales.

Por ejemplo, nos dice Alejandro Bertrand, en su calidad de Fiscal de Salitreras en 1892, que el senador por Tarapacá, Luis Aldunate ${ }^{18}$, admite "la necesidad de que se desprendiera el Estado de establecimientos industriales improductivos" y, citando al senador:

Que llegue algún día en el que, sin recurrir á combinaciones artificiales, ineficaces y odiosas, pueda el capital chileno interesarse en la utilización de estas riquezas que hasta hoy solo representan para el país el beneficio del impuesto, y que, en cambio, llevan íntegramente al extranjero pingües fortunas que, durante más de medio siglo, se han estado formando en su explotación (Bertrand 1892: XLIX).

Fue muy conocida la idea de los remates como un medio para incorporar capital chileno a la industria del salitre, después que abandonaran esta economía en los años de la “competencia salvaje” durante los años de incertidumbre previo y durante la Guerra del Pacífico, dejando el camino abierto a, precisamente, los capitalistas que organizaron el Trust salitrero y definieron la política salitrera a partir de 1884.

En el Consejo Salitrero, dependiente del Ministerio de Hacienda, se 
discutió en varias sesiones este tema, a saber:

El señor Subercaseaux dice que considera del mayor interés la iniciativa que se ha despertado en presencia del próximo remate de terrenos salitreros, de favorecer la nacionalización de la industria, facilitando á empresas chilenas la adquisición de pampas, iniciativa que apoyará y procurará por todos los medios que llegue a realizarse (Larraín 1912:XXIII).

Efectivamente los remates, tanto de oficinas salitreras como de terrenos con mantos de caliche, fueron cambiando la composición del grupo empresarial original. "La propiedad extranjera de la industria alcanzó su punto más alto a comienzos del decenio de 1890. A partir de ese momento los capitalistas chilenos fueron asumiendo una mayor parte en la industria al comprar nuevos campos de salitre en las subastas estatales” (Miller y Greehill 2010a:141). Probablemente, esa sea la causa que, enfrentados los empresarios a la profunda crisis salitrera de 1913/14, no fue posible volver a combinarse.

Ricardo Couyoumdjian nos recuerda que los productores tuvieron una reunión con el Ministro de Hacienda para decirles que pretendían reducir las existencias de salitre y no hacer subir el precio. "Sin embargo, el intento de restringir la producción fracasó, por cuanto los salitreros que se habían mantenido fuera de la combinación aprovecharon la oportunidad para aumentar la producción” (1986:16). Económicamente el problema era similar al de 1884, pero sociológicamente el grupo empresarial ya no era el mismo.

El gerente de la Asociación de Productores de Salitre, organización heredera de la Asociación Salitrera de Propaganda, Alfredo Santander, exponía en 1926 criticando "el grave inconveniente de las ventas individuales que creaban una competencia entre los mismos productores sin ventaja efectiva para el consumidor. Fue así que creció la especulación en salitre que en los años que precedieron a la guerra mundial, tomó, en algunos países y en algunas bolsas de comercio, caracteres de un verdadero juego" (1926:51). Entonces, ¿la solución era una combinación? O, como ya lo pensaban otros autores, la salida era la centralización de las ventas de salitre por el estado-nación (salitrero 1916). Al cabo de medio siglo ¿̇se pensaba en volver a un estanco salitrero parecido al propuesto por el Gobierno peruano de Manuel Pardo en 1873? ¿Qué fue en definitiva la COVENSA sino un estanco salitrero ${ }^{19}$

El período post-bélico, inaugurado con la crisis de 1919, fue definitivamente distinto, las percepciones de crisis no fueron producto de una política empresarial o de propaganda, sino de indicadores reales, se puede identificar una crisis entre 1920 y 1922, otra entre 1925 y1927, y la gran crisis desde 1929 y hasta1933. Fue el gobierno nacional el que tardíamente intervino para buscar la normalización de esta economía y de la vida social a través de una política de estado expresada en la COVENSA. 
Como lo desafían Rory Miller y Robert Greenhill, quizás sea posible pensar en "posibilidades contrafácticas”, ¿qué hubiese acontecido con una industria salitrera desarrollada naturalmente, sin combinaciones? Estos autores se preguntan: “¿Y qué tal si el Estado chileno hubiese intentado monopolizar las exportaciones o la producción del salitre en sus propias manos después de la Guerra del Pacífico?”, respondiendo que “lo más probable es que no habría querido asumir la responsabilidad directa de contratar el transporte y organizar la distribución” (2011a:161). Es decir, igual hubiese dependido, según ellos, de las grandes casas comerciales internacionales como la Gibbs. Estos autores no hacen mayor diferencia entre la economía del guano y la del salitre, tampoco entre los gobiernos del Perú y Chile. Habría cierto determinismo por el carácter mundial de las cadenas de mercancías para con las economías de países subdesarrollados. Empero, lo anterior no explica la necesidad de la creación de un cartel o trust salitrero por parte de los empresarios, la mayoría de ellos extranjeros, especialmente ingleses, excepto que con ello alcanzaran una posición estratégica no solo económica, sino fundamentalmente política, frente al estado-nación chileno de la época ${ }^{20}$.

Otra pregunta contrafactual es: $\dot{\mathrm{c}} \sin$ las combinaciones y la consecuente "normalización" de las crisis, habrían sobrevivido (como lo hicieron) salitreras pequeñas y con tecnologías más rudimentarias? No se puede afirmar tampoco si la propiedad salitre se hubiera concentrado en unas pocas compañías grandes, pero lo que sí es un dato innegable es la pérdida de competitividad general de la industria del nitrato chileno y la obsolescencia tecnológica desde que se crearon las combinaciones salitreras, imposibilitando la respuesta de esta industria al desafío tecnológico del salitre sintético. 


\section{Notas}

${ }^{1}$ Instituto de Estudios Internacionales (INTE). Universidad Arturo Prat. Proyecto Fondecyt N²1130517; e-mail pampino50@gmail.com

${ }^{2}$ Wallerstein entiende por crisis a "una circunstancia rara, la circunstancia en que un sistema histórico ha evolucionado hasta el punto que el efecto acumulativo de sus contradicciones internas impide que el sistema resuelva sus propios dilemas por medio de ajustes en sus patrones institucionales vigentes” (2007:146).

${ }^{3}$ Las percepciones, como nos enseña la sociología, si bien se trata de categorías sicosociales, temporales y privadas, a escala de grupos sociales o de toda una sociedad, tienden a normalizarse y pueden transformarse en permanentes y públicas (Galtung 1973).

${ }^{4}$ Concepto se basa en el utilizado por John Womack sobre la organización industrial y el movimiento obrero (2007:51)

${ }^{5}$ El primer intento por alcanzar un monopolio del salitre fue el realizado por el Gobierno del Perú presidido por Manuel Pardo (1872-1875), a través de una política de expropiación de las salitreras.

${ }^{6}$ Se reemplaza la Asociación Salitrera de Propaganda, con sede en Iquique, por la Asociación de Productores de Salitre, con sede en Valparaíso. Además el capital inglés comienza su retirada en favor el capital nacional.

7 Se inicia una discusión sobre la tributación salitrera al interior del Ministerio de Hacienda (Bertrand 1919).

${ }^{8}$ Para entonces todavía existían paradas salitreras en plena elaboración (Humberstone 1926).

${ }^{9}$ Las divergencias surgirán en la segunda y tercera combinaciones (Oliván 1893).

${ }^{10}$ Cuando se organizó la última combinación salitrera había aumentado significativamente el capital chileno, según datos del cónsul de S.M.B. Mr. Hudson, a saber: Británicos $£$ 10.700,000; chilenos $£ 10.500,000$; alemanes $£ 3.300,000$; varios $£ 3.000,000$ (Bertrand 1910:70). Lo anterior puede explicar en parte el fracaso de la combinación propuesta en 1913.

${ }^{11}$ Esta crisis irrumpió en 1884 y se prolongó hasta 1902 (Lluberes 1990).

${ }^{12}$ En libros posteriores Valdés Vergara cambió de posición respecto de esta medida, aproximándose más a una intervención del estado en esta industria (Valdés 1913).

${ }^{13}$ En cifras: en 1907 hubo una caída en la exportación de salitre respecto de 1906 de 1.727,459 toneladas métricas a 1.656,085. Por lo mismo, la Combinación Salitrera aumentó las cuotas de producción para 1908, alcanzando las 2.050,941 toneladas métricas. En 1907 no cayó la producción respecto de 1906, porque ésta fue de 1.846 y 1.822 toneladas métricas, respectivamente, como tampoco la cantidad de salitreras funcionando: 96 en 1906 y 110 en 1907, con excepción del mes de diciembre cuando 
paralizaron las salitreras de Tarapacá. Por cierto, el estado-nacional no vio afectada su renta salitrera, según Roberto Hernández, en 1906 el fisco recibió por estos derechos 180.492,152 millones de pesos en moneda corriente, siendo las rentas de la nación ese año $348.780,229$, es decir un 51,75\% fue lo que aportó el salitre y yodo (1930:177)

${ }^{14}$ Fue Fiscal de salitreras hasta la Guerra Civil de 1891, cuando fue destituido. Una vez reintegrado a la vida política nacional fue elegido diputado por Tarapacá en dos ocasiones, representado al Partido Liberal Balmacedista. Fue miembro de Consejo Salitrero.

${ }^{15}$ No tenemos espacio para mencionar las relaciones comerciales entre políticos chilenos (que incluye a presidentes de la República como Ramón Barros Luco) y compañías salitreras.

${ }^{16}$ También entre los obreros, pero por problemas de espacio no podemos abordar aquí este fenómeno.

${ }^{16}$ Una interesante polémica, con ribetes técnicos, se puede seguir en el periódico El Nacional de 1993, entre el Gerente de la Asociación Salitrera de Propaganda, Eduardo Vijil Z. y un personaje que se firma XX, ocultando s verdadera identidad. También participan de la polémica Gustavo Jullian, Delegado Fiscal de Salitreras, y Oscar Salbach, gerente de la compañía Fölch y Martin.

${ }^{18}$ Fue ministro de Domingo Santa María y le correspondió tramitar el importante decreto que constituyó la propiedad salitrera en Tarapacá a partir de 1882.

${ }^{19}$ Corporación de salitre y yodo, creada por Ley $\mathrm{N}^{\circ}$ 5.350, que estableció el estanco de la exportación de salitre y yodo en Chile el 8 de enero de 1934.

${ }^{20}$ Cabe señalar solamente la gran influencia que tuvieron algunos salitreros como Robert Harvey (Ramírez Necochea 1969) 


\section{Bibliografía}

Aldunate, C. (1907), Leyes, decretos y documentos relativos a la salitreras, Imprenta Cervantes, Santiago de Chile.

Araya, S. (2002), “Las representaciones sociales. Ejes teóricos para su discusión”. Cuadernos Sociales N¹27, FLACSO, Costa Rica.

Artaza et. al. (1998), A noventa años de los sucesos de la Escuela Santa María de Iquique, Editorial LOM, Santiago de Chile.

Bertrand, A. (1912), Tributación salitrera. Estudio acerca de su mejor adaptación al mercado post-bélico, Imprenta y Litografía Universo, Santiago de Chile.

Bertrand, A. (1892), Memoria acerca de condición actual de la propiedad salitrera en Chile, Imprenta Nacional, Santiago de Chile.

Bertrand, A. (1910), La crisis salitrera (1910). Estudio de sus causas y caracteres y de las condiciones favorables que caracterizan a la industria y comercio del salitre para evolucionar en el sentido de su concentración económica, Louis Michaud Editor, Paris.

Cadahia, L, y Velasco, G. (2012), Normalidad de la crisis/crisis de la normalidad, Katz Editores, Madrid.

Campaña, J.F. (1987), Memoria del delegado fiscal de salitreras presentada al señor Ministro de Hacienda en 1897, Imprenta Nacional, Santiago de Chile.

Cuadra, P.L. (1882), Informe de la Comisión Consultiva de guanos y salitres sobre las reclamaciones de ciudadanos, alemanes, franceses, italianos y españoles, en que piden revocación del decreto espedido por el Supremo Gobierno de Chile el 28 de marzo de 1882, Imprenta Nacional, Santiago de Chile.

Devés Valdés, E. (1988), Los que van a morir te saludan, Ediciones Documentas, Nuestra América Ediciones y América Latina Libros, Santiago de Chile.

Diáz Ossa, B. (1926), “La labor del Instituto Científico e Industrial del Salitre desde su fundación hasta hoy”, en Urzúa et. al. Semana del salitre celebrada en Santiago de Chile, abril 1926. Imprenta y Litografía La Ilustración, Santiago de Chile, 171-173.

Galtung, J. (1973), Teoría y método de investigación social, Editorial EUDEBA, Buenos Aires.

Humberstone, J.T. (1926), “Historia de la técnica salitrera en Chile”, en 
Darío Urzúa (compilación) Semana del Salitre. Organizada por la Academia de Ciencias Económicas, Santiago de Chile, Imprenta y Litografía La Ilustración, 1926, 121-123.

Hurtado, C. (1926), “Progresos en la industria salitrera”, en Urzúa et. al. Semana del salitre celebrada en Santiago de Chile, abril 1926, Imprenta y Litografía La Ilustración, 175-179, Santiago de Chile.

Larraín, J. (1912), Actas de las sesiones celebradas por el Consejo Salitrero durante el año 1912, Imprenta, Litografía y Encuadernación “Barcelona”, Santiago de Chile.

Lluberes, A. (1990), “La larga crisis azucarera, 1884-1902”, en Estudios Sociales $N^{\circ} 81$, Año XXIII, 20-65.

Matus, M. (2013), "Fulgor y muerte del jornal salitrero en Chile, 18991930”, en González, S. (compilador) La sociedad del salitre. Protagonistas, migraciones, cultura urbana y espacios públicos, 1870-1940, RIL Editores, 497-526, Santiago de Chile.

Miller, R. y Greenhill, R. (2011a), “Las cadenas de mercancías en los fertilizantes: el guano y el salitre 1840-1930”, en Miller, R. Empresas británicas, economía y política en Perú 1850-1934, IEP - BCRP, 116-164, Lima.

Miller, R. y Greenhill, R. (2011b), “Cómo se hizo el contrato Grace: el gobierno peruano y los acreedores británicos, 1885-1890”, en Miller, R. Empresas británicas, economía y política en Perú 1850-1934, IEP - BCRP, 165-202, Lima.

Oliván, F. (1893), La Combinación Salitrera: sus hechuras y lo que puede suceder, Tipografía Central, Valparaíso.

Ramírez Necochea, H. (1969), Balmaceda y contrarrevolución de 1891, Editorial Universitaria, Santiago.

Reyes, E. (1973), El desarrollo de la conciencia proletaria en Chile (el ciclo salitrero), Editorial Orbe, Santiago de Chile.

Rodríguez, J.C. y Miranda, P. (2010), “Patrimonio: entre la tregua melancólica y un lenguaje para la declinación. La transformación urbana de María Elena, norte de Chile”, en Revista Estudios Atacameños ํㅜ 40, 85-100.

Salinas, M. (1890), Memoria de la delegación fiscal de salitreras presentada al señor Ministro de Hacienda en el año 1890, Imprenta de "Los Debates”, Santiago de Chile.

Salitrero (1916), Industria del salitre. Intento de organización compulsiva por el Estado, Imprenta Universitaria, Santiago de Chile. 
Sánchez, D. (2012), “Modernidad, crisis y filosofía”, en Cadahia, L, y Velasco, G. Normalidad de la crisis/crisis de la normalidad. Katz Editores, 45-80, Madrid.

Schmidt, H. (1884), Memoria i Proyecto del presidente del Comité Salitrero sobre la propagación del consumo del salitre, Imprenta de El Veintiuno de Mayo, Iquique.

Valdés Vergara, F. (1913), Problemas económicos de Chile, Imprenta y Litografía Universo, Valparaíso.

Valdés Vergara, F. (1884), La crisis salitrera y las medidas que se proponen para remediarla, Imprenta de El Progreso, Santiago de Chile.

Velasco, G. (2012), “Crisis de la construcción social de la normalidad capitalista”, en Cadahia, L, y Velasco, G. Normalidad de la crisis/crisis de la normalidad, Katz Editores, 199-216, Madrid.

Wallerstein, I. (2007), Geopolítica y geocultura. Ensayos sobre el moderno sistema mundial, Editorial Kairós, Barcelona.

Womack, J. (2007), Posición estratégica y fuerza obrera. Hacia una nueva historia de los movimientos obreros, Fondo de Cultura Económica, México.

Periódicos citados:

La Libertad Electoral 1886-1889

El Nacional 1893

La Patria 1891-1893

Recibido: 20.02.2014

Aceptado: 10.09.2014 